ISBN: 978-1-948012-12-6

\title{
ANTIOXIDANT ACTIVITY OF POLYSACCHARIDE FROM CORN SILK IN VITRO
}

\author{
Li Ting, Zhou Hongli* \\ College of Chemical and Pharmaceutical Engineering, Jilin Institute of Chemical Technology Chengde Street, Jilin City, China. \\ *Corresponding Author Email: zhl67@126.com
}

This is an open access article distributed under the Creative Commons Attribution License, which permits unrestricted use, distribution, and reproduction in any medium, provided the original work is properly cited.

\section{ARTICLE DETAILS}

\section{Article History:}

Received 26 June 2018 Accepted 2 July 2018

Available online 1 August 2018

\section{ABSTRACT}

Study on antioxidant activity of the polysaccharide from corn silk in vitro. Methods:Use clearing thiobarbituric acid method, removing 2,2 '- azino-bis (3 - ethylbenzothiazoline-6 - sulfonic acid) diazonium salt (ABTS) radical, chelation ferrous ion ability and clearing DPPH free radicals methods, which vitamin C and EDTA were used as positive controls. Results: IC 50 (half inhibitory concentration) of lipid peroxidation,clearing ABTS radical, chelation ferrous ion ability and clearing DPPH radical were $5.424,4.618,6.056 \mathrm{mg} / \mathrm{mL}$. Conclusion: The polysaccharide of corn silk has the antioxidant activity,which is associated with the concentration of polysaccharide from corn silk.

\section{KEYWORDS}

Corn silk, polysaccharide, antioxidant effect, in vitro.

\section{INTRODUCTION}

At present, people are facing more and more health threats, such as radiation, environmental pollution, food additives, life pressure and so on, which is resulting in the proliferation of free radicals in vivo, more and more research on antioxidant in recent years. Because oxidation can cause directly damage to biological tissue and metabolism, free radicals can take hydrogen atoms with many substances in the organism, such as fatty acids and proteins so that the structure and function of related cells are changed, too. It is causes heart disease, Alzheimer's disease, diabetes, high blood pressure, mental illness, respiratory infections, cancer and aging. The research on antioxidant activity is becoming more and more important, so it is of great significance to find natural antioxidants, and polysaccharide has become a natural antioxidant with its various characteristics.

Corn silk is the dry style and stigma of the Gramineae maize (Zea mays L.), one of the commonly used medicinal herbs of the "People's Republic of China Ministry of Health Medicinal Materials Standard"]1985 Edition (Part One) [1]. It contains a variety of chemical constituents, such as volatile oil, saponins, alkaloids, flavonoids, polypentose, organic acids and so on. Corn silk can be used to treat diabetes, jaundice, measles, celiac hematuria, flooding and other disease [2]. Modern pharmacology research confirms that corn silk has the function of lowering blood sugar, lowering blood pressure, anti-tumor, anti-oxidation, enhancing immune function and delaying senility $[3,4]$. And corn silk is minimal toxicity and has very high medicinal value. The antioxidant activity of corn silk is linked to antioxidant substances including polysaccharides and peptides [5, 6].

\section{MATERIALS AND METHODS}

\subsection{Materials and instruments}

Corn silk (from the Longtan District of Jilin in 2017, maize, maize), 2-Thio barbiturates,2,2 '-N-union nitrogen gas (ethyl benzene and thiazole -6sulfonic acid) ammonium salt (ABTS)phenanthrene (Ferrozine American Sigma Company Import separation), ascorbic acid (VC), trichloroacetic acid, ferric chloride and other chemical reagents are analytically pure

\subsubsection{Extraction of polysaccharides}

The polysaccharide of corn silk was extracted with the temperature $90^{\circ} \mathrm{C}$ the ratio of solid to liquid 1:30, the extraction time $2 \mathrm{~h}$ and extraction time 2 times. The two aqueous extracts were combined, concentrated to $1 / 5$ of total volume, and $95 \%$ ethanol was added to a solution until the ethanol concentration was $80 \%$. The crude polysaccharide powder was obtained under a $4^{\circ} \mathrm{C}$ environment, centrifugation, freeze-drying in vacuum.

\subsubsection{Content Determination}

The content of the polysaccharides was determined by phenol sulfuric acid and glucose as standard [7]. The sample solution $0.5 \mathrm{~mL}$ (blank as distilled water) was taken, and then $1 \mathrm{~mL} 5 \%$ phenol reagent and the $3.5 \mathrm{~mL}$ concentrated sulfuric acid were added, shaked well. The mixture liquid was heated at $40{ }^{\circ} \mathrm{C}$ water bath for $30 \mathrm{~min}$ and was cooled for $15 \mathrm{~min}$. The absorbance $A$ of reaction liquid was measured at $490 \mathrm{~nm}$ wavelength by ultraviolet visible spectrophotometer and 3 times in parallel.

\subsubsection{Evaluation of antioxidant activity in vitro}

\subsubsection{Thiobarbituric acid radical scavenging activity [8]}

The $0.2 \mathrm{~mL}$ dilute yolk suspension was mixed with the $1 \mathrm{~mL}$ sample solution of $1 \mathrm{mg} / \mathrm{mL}, 2 \mathrm{mg} / \mathrm{mL}, 3 \mathrm{mg} / \mathrm{mL}, 4 \mathrm{mg} / \mathrm{mL}$ and $4.5 \mathrm{mg} / \mathrm{mL}$ respectively, and $0.2 \mathrm{~mL} 25 \mathrm{mmoL} / \mathrm{L}$ sulphate solution and $2 \mathrm{~mL} 0.2 \mathrm{~mol} / \mathrm{L}$ PBS of pH7.4 were added, then the mixtures were preservated at $37^{\circ} \mathrm{C}$ water bath for $30 \mathrm{~min}$, lastly $5 \mathrm{ml} 2.5 \mathrm{~mL} 1 \%$ potassium ferricyanide was added to the above solution. The mixtures were placed at $50^{\circ} \mathrm{Cwater}$ bath for $20 \mathrm{~min}$, then $0.5 \mathrm{~mL} 20 \%$ three chloroacetic acid (TCA) was added. After the above solution centrifuge 8 minutes in $5000 \mathrm{r} / \mathrm{min}, 2.0 \mathrm{~mL}$ supernatant was added to $1.0 \mathrm{~mL} 0.8 \%$ thiobarbituric acid, and then was heated by boiling water for $15 \mathrm{~min}$ and cooled, $\mathrm{A}_{1}$ was measured at $532 \mathrm{~nm}$ and $A_{0}$ in distilled water instead of sample solution as blank control. Replacement of thiobarbituric acid with $1 \mathrm{~mL}$ distilled water as group of modulating 0 . Vitamin $\mathrm{C}$ as positive control was determined with the same method. Each concentration was parallel determined three time, and then the average was taken. The clearance rates of samples and vitamin $\mathrm{C}$ were calculated according to the following formula:

Scavenging rate $(\%)=\left(\mathrm{A}_{0}-\mathrm{A}_{1}\right) / \mathrm{A}_{0} \times 100 \%$

2.2.3.2 ABTS radical scavenging activity [9]

$5 \mathrm{~mL} 7 \mathrm{mmoL} / \mathrm{L}$ ABTS and $88 \mu \mathrm{L} 140 \mathrm{mmoL} / \mathrm{L}$ potassium persulfate were 
mixed to keep away from light overnight (12-16h) in room temperature. The reserve liquid of ABTS free radical was formed, then the ABTS working solution was diluted to 50 with distilled water. The absorbance was $0.7 \pm 0.02$ of $734 \mathrm{~nm}$ wavelength at $30^{\circ} \mathrm{C}$.

In the sample tube, the $200 \mu$ (concentration $0.1 \mathrm{mg} / \mathrm{mL}, 0.5 \mathrm{mg} / \mathrm{mL}$, $1.0 \mathrm{mg} / \mathrm{mL}, 1.5 \mathrm{mg} / \mathrm{mL}, 2.0 \mathrm{mg} / \mathrm{mL}, 2.5 \mathrm{mg} / \mathrm{mL}, 3.0 \mathrm{mg} / \mathrm{mL}$ ) with the sample solution of polysaccharide of different concentrations was added into $3 \mathrm{~mL}$ ABTS working solution. The control tube was used distilled water instead of ABTS working solution. The above tubes were placed $1 \mathrm{~h}$ in dark at room temperature, and absorbance was measured at the wavelength of $734 \mathrm{~nm}(\mathrm{~A})$. The same method was used to measured the absorbance of vitamin $\mathrm{C}$ in positive control, and the average value was measured 3 times in parallel. Sample and vitamin C for ABTS free radical clearance rate was calculated according to the following formula:

Scavenging activity $(\%)=A_{0}-\left(A_{i}-A_{j}\right) / A_{0} \times 100 \%$

2.2.3.3 Chelated ferrous ion [10]

The crude polysaccharide of $10.0 \mathrm{mg}$ was prepared for different concentration solution $(0.25,0.5,1,2,3,4,5$, and $6.0 \mathrm{mg} / \mathrm{mL})$ into distilled water, each $1 \mathrm{~mL}$ solution was added into $1 \mathrm{~mL} 0.1(\mathrm{mmoL} / \mathrm{L})$ ferrous sulfate solution, $1 \mathrm{~mL} 0.25 \mathrm{mmoL} / \mathrm{L}$ philoxin methanol solution, and mixed fully, then placed in the dark place for 10min. EDTA as the positive control was measured the absorption value at $562 \mathrm{~nm}$. $1 \mathrm{~mL}$ distilled water was instead of sample solution as blank control and $1 \mathrm{ml}$ distilled water was substituted for ferrous sulfate as the sample control.The chelating rate was calculated in the following formula:

Chelate rate $(\%)=\left[A_{0}-\left(A_{1}-A_{2}\right)\right] / A_{0} \times 100 \%$

In the formula, $A_{0}$ is a blank control absorption value, $A_{1}$ is the sample absorption value, $A_{2}$ is thecontrol absorption value.

\subsubsection{DPPH radical scavenging activity [11]}

The basic steps were that the series concentration $(20 \mu \mathrm{g} / \mathrm{mL}, 40 \mu \mathrm{g} / \mathrm{mL}$, $60 \mu \mathrm{g} / \mathrm{mL}, 80 \mu \mathrm{g} / \mathrm{mL} 100 \mu \mathrm{g} / \mathrm{mL}$ ) of the polysaccharide solution $2 \mathrm{~mL}$ was added into $0.1 \mathrm{mmol} / \mathrm{L}$ DPPH solution of the equal volume (anhydrous ethanol) $[12,13]$. After blending at room temperature to avoid lighting reaction for $30 \mathrm{~min}$, the absorbance $A_{i}$ was determine at $517 \mathrm{~nm}$, and $4 \mathrm{~mL}$ anhydrous ethanol and distilled water (respectively, $2 \mathrm{~mL}$ ) was adjusted zero. In the blank control group, the $2 \mathrm{~mL}$ sample solution was added with $2 \mathrm{~mL}$ anhydrous ethanol, and the absorbance value of the blank control group was at $517 \mathrm{~nm}$. The model control group was added into $2 \mathrm{~mL} \mathrm{DPPH}$ solution and $2 \mathrm{~mL}$ anhydrous ethanol, and its absorbance value at $517 \mathrm{~nm}$ was $\mathrm{A}_{0}$. The same method was used to measure the absorbance of Vitamin C (series concentration of $2 \mu \mathrm{g} / \mathrm{mL}, 4 \mu \mathrm{g} / \mathrm{mL}, 6 \mu \mathrm{g} / \mathrm{mL}, 8 \mu \mathrm{g} / \mathrm{mL}, 10 \mu \mathrm{g} / \mathrm{mL}$ ), and the average value was measured 3 times. The clearance rate of sample and vitamin $\mathrm{C}$ was calculated according to the following formula:

\section{Scavenging activity $(\%)=1-\left(A_{i}-A_{j}\right) / A_{0} \times 100 \%$}

\section{RESULTS AND DISCUSSION}

\subsection{Polysaccharide content}

The polysaccharides were extracted using optimal technological conditions [14]. Regression equation $\mathrm{Y}=0.1547 \mathrm{Cx}+0.9998$ ( $\mathrm{Cx}$ units $\mathrm{mg} / \mathrm{mL}$ ), the polysaccharide purity was $29.60 \%$.

\subsection{The antioxidant activity of corn silk polysaccharide in vitro}

\subsubsection{Thiobarbituric acid radical scavenging activity}

Main product of lipid peroxidation (TBA method) is lipid peroxide (LPO), which is the product of the reaction of oxygen radicals and polyunsaturated fatty acids. Under the normal conditions, the content of LPO is very low, but in the case of pathological changes, the increase of lipid peroxidation can lead to the increase of LPO, which may cause serious damage to the structure and function of cells and cell membranes. The normal range of human LPO measured by the TBA method is 1.6-5.2 $\mathrm{mmol} / \mathrm{L}$.
Figure 1 (a ) showed the polysaccharides of corn silk had a certain inhibition rate of LPO, its inhibition rate of LPO within a certain range increased with the increase of polysaccharide concentration, maximum LOP inhibition rate when the concentration was $3 \mathrm{mg} / \mathrm{ml}$. Then, with the increase of polysaccharide concentration, the inhibition rate of LPO decreased. Under the same conditions, the inhibition rate of LPO with 3.0 $\mathrm{mg} / \mathrm{mL} \mathrm{VC}$ was $71.25 \%$, while the inhibitory rate of polysaccharides with the same concentration was $58.79 \%$. The $\mathrm{IC}_{50}$ of the polysaccharides and vitamin C were $5.424 \mathrm{mg} / \mathrm{mL}$ and $5.304 \mathrm{mg} / \mathrm{mL}$. The experiments showed that the polysaccharides of corn silk had a certain inhibition rate of LPO, but weaker than VC.
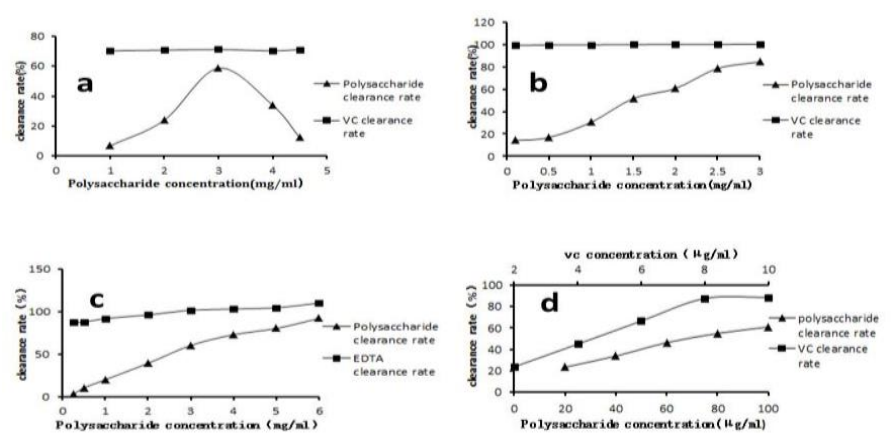

Figure 1: Thiobarbituric acid (a), ABTS radical scavenging activity (b), Chelated ferrous ion(c), DPPH (d)

\subsubsection{ABTS radical scavenging activity}

The ABTS radical is a relatively stable radical obtained by oxidation of ABTS-(NH3)2. When a radical scavenger is added to the solution, the absorbance of the solution at $752 \mathrm{~nm}$ becomes smaller or disappear. The degree of change and the sample concentration show a good linear relationship.

Figure1 (b) showed the removal rate of ABTS free radicals was $14.21 \%$ (VC $99.31 \%$ ) at a concentration of $0.1 \mathrm{mg} / \mathrm{mL}$, and the maximum clearance rate was basically reached at a concentration of $3.0 \mathrm{mg} / \mathrm{mL} 84.50 \%$ (VC $100.36 \%$ ). The IC 50 of the polysaccharides and VC were $4.618 \mathrm{mg} / \mathrm{mL}$ and $4.055 \mathrm{mg} / \mathrm{mL}$, indicated that the polysaccharides had an ability to eliminate ABTS free radicals. However, the removal effect was not so better as VC. Scavenging capacity of ABTS free radicals increased with the increasing of polysaccharide concentration within a certain range, expressing the linear relationship.

\subsubsection{Chelated ferrous ion}

The presence of metal ions can accelerate the rate of oxidation of lipid compounds, so its antioxidant activity can be evaluated by measuring the effect of antioxidants in removing metal ions. The chelation efficiency is determined using the phenazine method to evaluate the antioxidant effect of the polysaccharide.

Figure 1 (c) showed the polysaccharide had a certain reduction ability of iron ions which significantly weaker than EDTA. When the concentration of the polysaccharide reached $6 \mathrm{mg} / \mathrm{ml}$, its chelation ability was similar to EDTA. As the polysaccharide concentration increased, the reduction of iron ions increased, which showed a dose-effect relationship. The $\mathrm{IC}_{50}$ of the polysaccharide and EDTA was $7.056 \mathrm{mg} / \mathrm{mL}$ and $5.501 \mathrm{mg} / \mathrm{mL}$.

\subsubsection{DPPH radical scavenging activity}

The DPPH method is a fast, simple, sensitive, and feasible method for evaluating the antioxidant activity of natural antioxidants and it is widely used at home and abroad. DPPH radical is a kind of stable organic radical, which have a characteristic purple-red cluster absorption peak in ethanol solution. When a free radical scavenger is presented, its absorption gradually disappeares due to its pairing with a single electron, and it is the quantitative relationship between the degree of fading and the number of electrons accepted,thus the spectrophotometric method can be used. 
Figure 1 (d) showed the polysaccharide had a strong ability to scavenge DPPH free radicals, and the clearance rate was linearly related to the polysaccharide concentration. In a certain range, the clearance rate increased with the increase of the polysaccharide and VC concentration. When the polysaccharide concentration was about $80 \mu \mathrm{g} / \mathrm{ml}$, the clearance rate reached the maximum, and then arrived at a stable level. The maximum removal rate was observed when the VC concentration was 100 $\mu \mathrm{g} / \mathrm{ml}$. The IC $\mathrm{C}_{50}$ of the polysaccharide of corn silk and VC were $0.141 \mu \mathrm{g} / \mathrm{ml}$ and $0.014 \mu \mathrm{g} / \mathrm{mL}$, respectively. The polysaccharide clearance was significantly weaker than VC.

\section{CONCLUSION AND DISCUSSION}

In this study, four kinds of antioxidant methods in vitro were used to estimate the antioxidant activity of the polysaccharide of corn silk. The results showed that the polysaccharide of corn silk has a good inhibitory effect on lipid peroxidation and showed good antioxidant activity in the antioxidant system of thiobarbituric acid. The inhibition rate of LPO increased with the increasing of concentration in a certain concentration range. The polysaccharide of corn silk also has a definite reducing ability and has a good scavenging effect on ABTS radicals. In terms of the two methods of scavenging ABTS radicals and chelating ferrous ions, the removal rate of ABTS radicals and the chelation rate of ferrous ions was related to the concentration of the polysaccharide of corn silk. The concentration-removal rate and chelation rate showed a dose-effect relationship within a certain concentration range. The polysaccharide of corn silk has a good clearance rate for DPPH free radicals, but its antioxidant activity was weaker than VC. Based on the above experimental results, the polysaccharide of corn silk has a certain degree of antioxidation, which provided a scientific basis for the development and utilization of corn silk and proved that it may have research value.

\section{ACKNOWLEDGMENTS}

This study was financed by Jilin provincial development and Reform Commission (Grant No. 2017C044).

\section{REFERENCES}

[1] Guo, X., Gang, H.E., Yang, Y., Zhao, Q., Liangang, W.U., Gou, X. 2013. Preparation of corn silk polysaccharides and study on their anti-oxidative activity in vitro. Journal of Sichuan Normal University, 36 (05),767-771.
[2] Jia, Y.M., Zhu, Y.X., Guo, Y.H. 2010. Physical and chemical properties of corn silk polysaccharide and its immunity activity. Journal of China Agricultural University, (04), 20-24.

[3] Zhao, W.Z., Yin, Y.G., Yu, Z.P., Liu, J.B., Chen, F. 2012. Comparison of antidiabetic effects of polysaccharides from corn silk on normal and hyperglycemia rats. International Journal of Biological Macromolecules, 50 (4), 1133-1137.

[4] Chen, H., Zhang, M., Xie, B. 2005. Components and antioxidant activity of polysaccharide conjugate from green tea. Food Chemistry, 90 (1-2), 17 21.

[5] Kardošová, A., Machová, E. 2006. Antioxidant activity of medicinal plant polysaccharides. Fitoterapia, 77 (5), 367-373.

[6] Bhaigyabati, T., Kirithika, T., Ramya, J., Usha, K. 2011. Phytochemical constituents and antioxidant activity of various extracts of corn silk (zea mays 1). Research Journal of Pharmaceutical Biological \& Chemical Sciences, 2 (4), 986-993.

[7] Chi, Y., Wang, L.B. 2014. Study on phenol-sulfuric acid method for determination of polysaccharide content in pumpkin seeds [j]. Food \& Machinery, 30 (01), 89-92.

[8] Tannin-Spitz, T., Bergman, M., Van-Moppes, D., Grossman, S., Arad, S. 2005. Antioxidant activity of the polysaccharide of the red microalga porphyridium, sp. Journal of Applied Phycology, 17 (3), 215-222.

[9] Miller, N.J., Sampson, J., Candeias, L.P., Bramley, P.M., Riceevans, C.A 1996. Antioxidant activities of carotenes and xanthophylls. Febs Letters, 384 (3), 240-242.

[10] Cao, J.Z., Wei, L., Hong, S.U., Fan, L., Yu, L.I. 2011. Study on extraction and anti-oxidant activity of crude polysaccharides from tuber indicum. Journal of Shanxi University, 34 (1), 137-142.

[11] He, Y.T., Gao, H.N., Xu, Y.X., Pan, X.M., Li, J.R. 2012. Chemical analysis and antioxidant activities in vitro of polysaccharide extracted from corn silk. Advanced Materials Research, 535-537, 2335-2339.

[12] Li, X.L., Zhou, A.G., Han, Y. 2006. Anti-oxidation and antimicroorganism activities of purification polysaccharide from lygodium japonicum, in vitro. Carbohydrate Polymers, 66 (1), 34-42. 